\title{
The challenges of estimating the prevalence of child maltreatment
}

\author{
Gwenllian Moody*, Michael Robling, Kerenza Hood, Rebecca Cannings-John, Alison Kemp \\ From 3rd International Clinical Trials Methodology Conference \\ Glasgow, UK. 16-17 November 2015
}

\begin{abstract}
Aims
Counting a condition that has no gold standard diagnostic test such as child maltreatment presents challenges. This literature review aims to review both formally collected statistics from agencies in the UK, and studies using various methodologies to capture prevalence rates in the UK and worldwide.

\section{Methods}

PubMed, Ovid SP and grey literature from the NSPCC, UNICEF, The UK Government, and WHO were reviewed from 1989 to 2014. A 'snowballing' technique was used to identify additional studies. The literature review focused on the various ways maltreatment data are collected in the UK from official statistics, to the variation found in selfreported prevalence of maltreatment between studies worldwide, and how methodological differences may explain differences found in the quoted prevalence figures.
\end{abstract}

\section{Results}

Official statistics of maltreatment in the UK are only a portion of the true cases. Self-reported prevalence rates are also used to collect data, however, rates vary between studies. Studies conducted in the UK report that between $0.8 \%$ to $25 \%$ of children have a lifetime prevalence rate of maltreatment (sexual, physical, and emotional abuse, and neglect), studies conducted worldwide showed even greater variation of between $0.2 \%$ and $77 \%$.

\section{Discussion}

Official statistics on maltreatment include only the tip of the iceberg of true cases. Self-report studies can also be used to estimate maltreatment, however, prevalence rates differ vastly between studies, this is likely due to methodological differences, which include the data

Submit your next manuscript to BioMed Central and take full advantage of:

- Convenient online submission

- Thorough peer review

- No space constraints or color figure charges

- Immediate publication on acceptance

- Inclusion in PubMed, CAS, Scopus and Google Scholar

- Research which is freely available for redistribution 